\title{
Precipitation and Dissolution Kinetics of GP Zones and Metastable Phase in Al-3wt.\%Cu Alloy
}

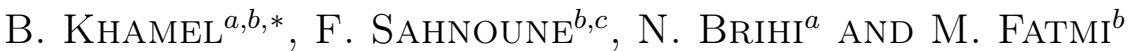 \\ ${ }^{a}$ Department of Physics, University Mohamed Seddik Ben Yahia of Jijel, Jijel 18000, Algeria \\ ${ }^{b}$ Research Unit on Emerging Materials (RUEM), Ferhat Abbas of Setif 01, Setif 19000, Algeria \\ ${ }^{c}$ Physics Department, Faculty of Science, University Mohamed Boudiaf of M'sila, 28000 M'sila, Algeria

\begin{abstract}
The kinetic parameters such as activation energy $E$ and the growth morphology parameters $n$ and $m$ were determined by a non-isothermal method. The microstructure variations of the precipitation and dissolution of GP zone and metastable phase $\theta^{\prime}$ in $\mathrm{Al}-3 \mathrm{wt} . \% \mathrm{Cu}$ were analyzed by optical microscopy and X-ray diffraction. The kinetics of GP zone and metastable phase $\theta^{\prime}$ in Al-3wt.\% $\mathrm{Cu}$ was investigated using differential thermal analysis between room temperature and $430^{\circ} \mathrm{C}$ at heating rates of 20,25 and $30^{\circ} \mathrm{Cmin}^{-1}$. The activation energies of GP zone precipitation, formation of $\theta^{\prime} / \theta$ and dissolution of $\theta^{\prime}$ were 26,105 and $77 \mathrm{kJmol}^{-1}$, respectively. The growth morphology parameters $n$ (Avrami parameter which indicates the crystallization mode) and $m$ (a numerical factor which depends on the dimensionality of crystal growth) are both about 1.5 .
\end{abstract}

DOI: 10.12693/APhysPolA.134.45

PACS/topics: differential thermal analysis (DTA), precipitation, activation energies

\section{Introduction}

Aluminum alloys have potential applications in various portable devices and vehicles due to their high strength and low weight. Precipitation hardening by heat treatment is critical in optimizing mechanical performance to achieve rational design $[1,2]$. The $\mathrm{Al}-\mathrm{Cu}$ alloy system has one of the most complex precipitation sequences of all age hardenable aluminum alloys [3].

The precipitation sequence observed on aging these alloys is, supersaturated solid solution $\rightarrow$ Guinier-Preston (GP) I zones (GPI zones) $\rightarrow$ (GPII zones) $\rightarrow \theta^{\prime} \rightarrow \theta[4]$. Guinier-Preston has different morphologies (platelets, spheres, needles) depending on the difference in atomic diameters of solute and solvent elements [5]. The GP zones in $\mathrm{Al}-\mathrm{Cu}$ alloys still attract much interest and definitive conclusions on their structure, formation and evolution have not yet been reached $[5,6]$.

The $\theta^{\prime}$ phase of Al-Cu alloys is the favorite model system for studying the theories or mechanisms of phase transformation in aluminum alloys [7]. The structure of the $\theta$ phase with the composition $\mathrm{Al}_{2} \mathrm{Cu}$ was originally revealed by Friauf [7]. It was found to be tetragonal and stable up to $591{ }^{\circ} \mathrm{C}$ according to Murray [8].

Differential thermal analysis (DTA) has been frequently employed in recent times for the determination of kinetic parameters of thermally activated processes like the precipitation reactions and the activation energies. This method is based on the difference in heat required to increase the temperature of a sample and

*corresponding author; e-mail: khamelbillal@yahoo.com a reference material, respectively [9]. Our present contribution contains various calculated kinetic parameters. The measured parameters have been used the methods of Kissinger, Ozawa and Boswell under non isothermal conditions using the DTA.

\section{Materials and experimental procedure}

The composition of impurities of the Al-Cu alloy prepared for this work is listed in Table I. These alloys have been prepared in our laboratory by fusion in a high vacuum $\left(10^{-5}\right.$ Torr $)$ using pure materials.

After melting, the ingots have undergone plastic deformation by cold rolling before the homogenization treatment in order to accelerate the structure homogenization kinetics. The homogenization temperature and aging were chosen from the equilibrium diagrams. For obtaining a super saturated solid solution, the ingots were homogenized in vacuum at $430^{\circ} \mathrm{C}$ for $3 \mathrm{~h}$ and quenched in water; we have prepared a disc shaped sample of $3 \mathrm{~mm}$ in diameter and $1 \mathrm{~mm}$ thickness for DTA.

DTA experiments were performed using Setaram Labsys Evo TG-DTA $1600^{\circ} \mathrm{C}$ equipment. Representative sections of annealed samples were investigated by means of a JEOL scanning electron microscope (SEM) model JMS 6400. The X-ray diffraction analysis was performed using a diffractometric system XPERT-PRO with scan step size of $0.0167\left(\mathrm{Cu}_{K \alpha}\right.$ radiation and a Ni filter), operated at $40 \mathrm{kV}$ and $40 \mathrm{~mA}$.

\section{Results and discussion}

Figure 1 shows typical DTA curves of Al-3wt.\% Cu alloy from room temperature to $400^{\circ} \mathrm{C}$ at heating rates of 20, 25 and $30^{\circ} \mathrm{Cmin}^{-1}$. Two exothermic peaks (A, B) 
and an endothermic peak (C) were observed. The peak (A) from $107^{\circ} \mathrm{C}$ to $135^{\circ} \mathrm{C}$ is due to the precipitation of $\mathrm{GP}$ zone. The peak (B) from $275^{\circ} \mathrm{C}$ to $285^{\circ} \mathrm{C}$ corresponds to the precipitation of $\theta^{\prime} / \theta$ phases and the peak (C) is due to the dissolution of $\theta^{\prime}$ from $304^{\circ} \mathrm{C}$ to $319^{\circ} \mathrm{C}$. The temperature of the maximum of the exothermic peak, $T_{\mathrm{p}}$, shifts to a higher temperature as the heating rate increases from 20 to $30^{\circ} \mathrm{Cmin}^{-1}$.

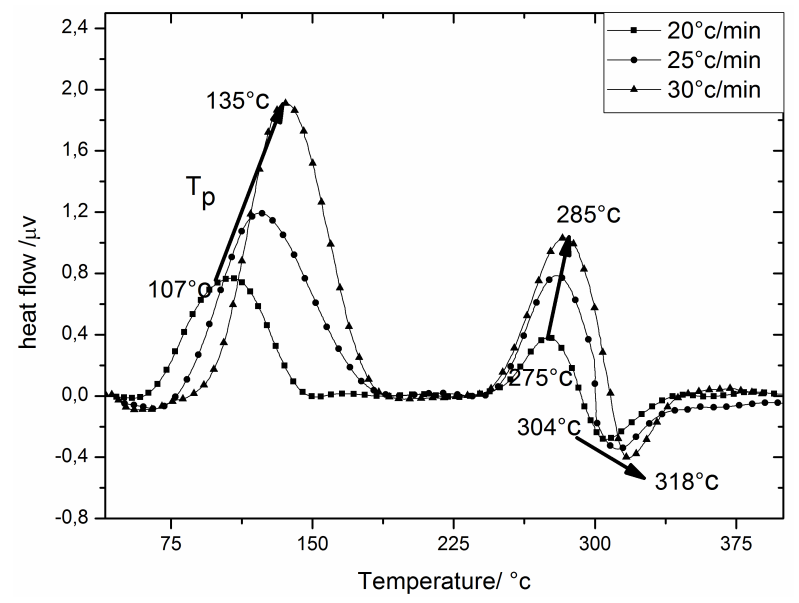

Fig. 1. DTA curves of Al-3wt.\% Cu alloy heated at different heating rates.

The X-ray diffraction patterns for Al-3wt.\% Cu homogenized during $3 \mathrm{~h}$ at $430^{\circ} \mathrm{C}$, quenched and aged at $150^{\circ} \mathrm{C}$ are shown in Fig. 2. The $\theta^{\prime}$ phase is present in the matrix. After prolonged ageing of $50 \mathrm{~h}$ at $150^{\circ} \mathrm{C}$, the diffraction peaks of $\theta$ phase show high intensity and the $\theta^{\prime}$ phase has disappeared. This explains that there are some amounts of precipitated phase. The microstructure of Al-3wt.\% Cu alloy, homogenized for $3 \mathrm{~h}$ at $420^{\circ} \mathrm{C}$, quenched in water and aged for $6 \mathrm{~h}$ at $150^{\circ} \mathrm{C}$ is presented in Fig. 3a and b, respectively.

TABLE I

Chemical composition of Al-3wt.\% Cu alloy.

\begin{tabular}{c|c|c|c|c}
\hline \hline Element & $\mathrm{Al}$ & $\mathrm{Cu}$ & $\mathrm{Si}$ & $\mathrm{Fe}$ \\
\hline Composition [wt.\%] & 96.79 & 3 & $<0.10$ & $<0.11$
\end{tabular}

For a non-isothermal DTA experiment, according to Kissinger Eq. (1), Ozawa Eq. (2) and Boswell Eq. (3) methods [10-12]:

$$
\begin{aligned}
& \ln \left(\frac{\phi}{T_{\mathrm{p}}^{2}}\right)=-\frac{E_{\mathrm{A}}}{R T_{\mathrm{p}}}+C_{3}, \\
& \ln (\phi)=-1.0518 \frac{E_{\mathrm{A}}}{R T_{\mathrm{p}}}+C_{1}, \\
& \ln \left(\frac{\phi}{T_{\mathrm{p}}}\right)=-\frac{E_{\mathrm{A}}}{R T_{\mathrm{p}}}+C_{2},
\end{aligned}
$$

where $C_{1}, C_{2}$ and $C_{3}$ are constants, $T_{\mathrm{p}}$ is the peak temperature, $E$ is the activation energy and $n$ is the Avrami parameter which indicates the crystallization mode.

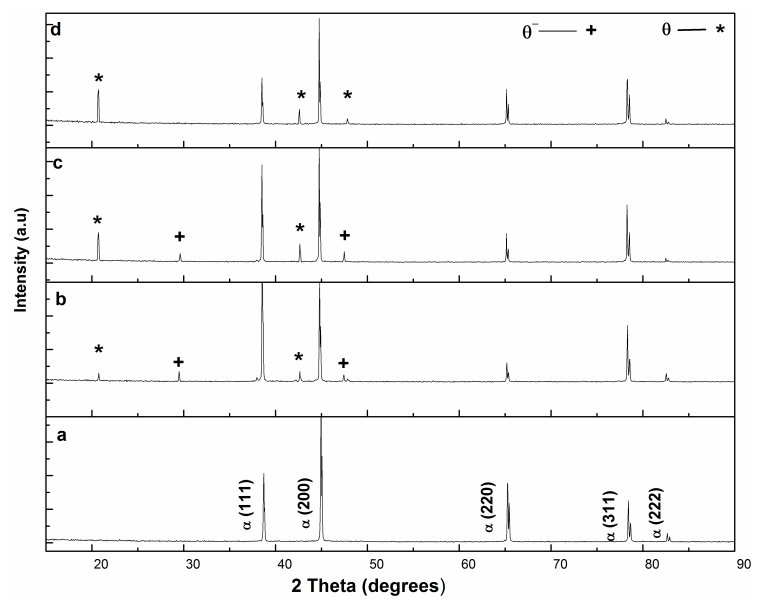

Fig. 2. X-ray diffraction patterns of Al-3wt.\% Cu alloy, homogenized at $430^{\circ} \mathrm{C}$ for $3 \mathrm{~h}$ quenched in water (a), aged for $3 \mathrm{~h} \mathrm{(b),} 6 \mathrm{~h} \mathrm{(c)} \mathrm{and} 50 \mathrm{~h}(\mathrm{~d})$ at $150^{\circ} \mathrm{C}$.

A plot of $Y$ versus $1 / T_{\mathrm{p}}$ should be a linear curve, whose slope yields the activation energy $E$. The plots of $Y$ versus $1 / T_{\mathrm{p}}$ according to Kissinger-Akahira-Sunose (KAS), Ozawa-Flynn-Wall (OFW) Ozawa and Boswell methods of (a) precipitation of GP zone, (b) formation of $\theta^{\prime} / \theta$ and (c) dissolution of $\theta^{\prime}$ in Al-3wt.\% $\mathrm{Cu}$ are visualized in Fig. 4.

The values of the activation energies calculated according to Kissinger, Ozawa and Boswell methods are listed in Table II. The activation energies evaluated through non-isothermal DTA were 26, 109 and $77 \mathrm{kJmol}^{-1}$ for GP zone precipitation, formation of $\theta^{\prime} / \theta$ and dissolution of $\theta^{\prime}$ respectively. These values are in good agreement with those estimated by isothermal DTA treatment [13].

The values of the Avrami parameter $n$ which indicates the crystallization mode for different heating rates are listed in Table III. These values were determined using Eq. (4).

$$
n=\frac{2.5 T_{\mathrm{p}}^{2} R}{\Delta T_{\mathrm{p}} E_{\mathrm{A}}}
$$

where $\Delta T$ is the width of crystallization peak at half maximum. The average Avrami parameter is equal to 1.49 for the formation of $\theta^{\prime} / \theta$. This value is closer to 1.5 , which suggests that the process of formation of $\theta^{\prime} / \theta$ is diffusion controlled. This value is in good agreement with that estimated by isothermal DTA treatment and with the work of M. Fatmi et al. [14].

The dimensionality of crystal growth $m$ calculated from the slope of the function $\ln \left(\phi_{n} / T_{\mathrm{p}}^{2}\right)=f\left(1 / T_{\mathrm{p}}\right)$, according to Matusita method [15] (see Eq. (5)) is found to be equal to 1.58 for the formation of $\theta^{\prime} / \theta$. This value is closer to 1.5 indicating that bulk nucleation is dominant in $\theta^{\prime} / \theta$ formation followed by three-dimensional.

$$
\ln \left(\frac{\phi^{n}}{T_{\mathrm{p}}^{2}}\right)=C_{3}-\frac{m E_{\mathrm{A}}}{R T_{\mathrm{p}}} .
$$



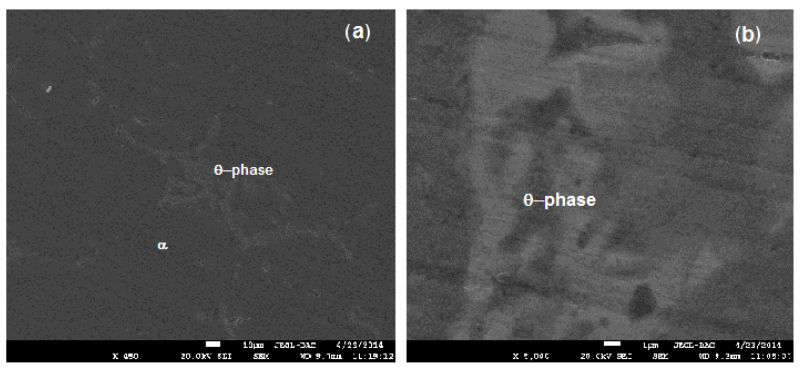

Fig. 3. Microstructure of Al-3wt.\% Cu alloy (a) and the same alloy homogenized for $3 \mathrm{~h}$ at $420^{\circ} \mathrm{C}$ (b), quenched in water and aged for $6 \mathrm{~h}$ at $150^{\circ} \mathrm{C}$.
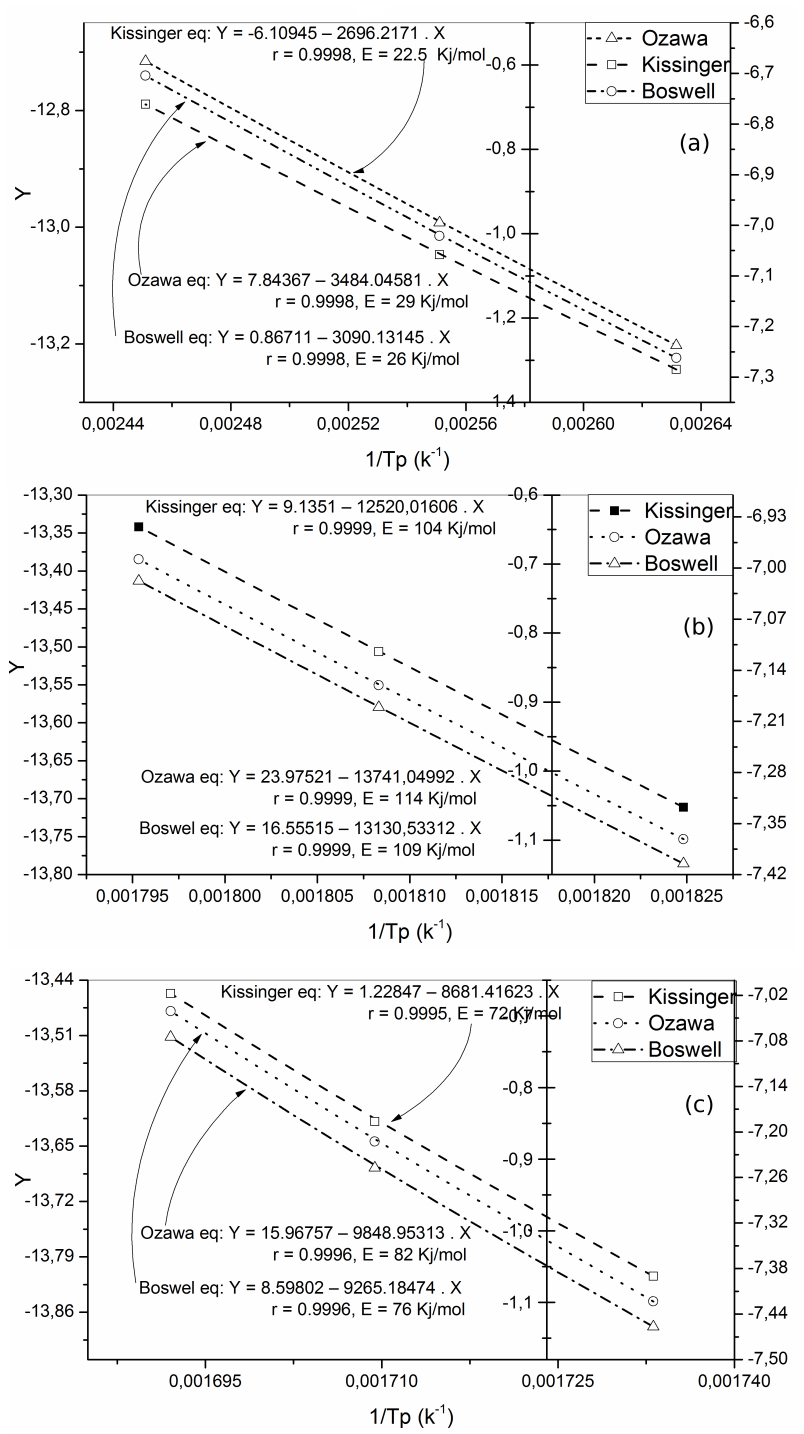

Fig. 4. Plots of $Y$ versus $1 / T_{\mathrm{p}}$ of (a) precipitation of GP zone, (b) formation of $\theta^{\prime} / \theta$ and (c) dissolution of $\theta^{\prime}$ in $\mathrm{Al}-3 \mathrm{wt} . \% \mathrm{Cu}$, calculated using three different methods.
Activation energies given by Kissinger, Ozawa and Boswell methods $\left(\mathrm{kJ} \mathrm{mol}^{-1}\right)$.

\begin{tabular}{l|c|c|c}
\hline \hline Method & $\begin{array}{c}\text { Precipitation } \\
\text { of GP zone }\end{array}$ & $\begin{array}{c}\text { Formation } \\
\text { of } \theta^{\prime} / \theta\end{array}$ & $\begin{array}{c}\text { Dissolution } \\
\text { of } \theta^{\prime}\end{array}$ \\
\hline Kissinger & 22.5 & 104 & 72 \\
Ozawa & 29 & 114 & 82 \\
Boswell & 26 & 109 & 76
\end{tabular}

TABLE III

Values of the Avrami parameter $n$ for different heating rates from DTA experiments.

\begin{tabular}{l|c|c|c}
\hline \hline Heating rates & $20^{\circ} \mathrm{C} / \min$ & $25^{\circ} \mathrm{C} / \min$ & $30^{\circ} \mathrm{C} / \mathrm{min}$ \\
\hline$\Delta T$ & 38.834 & 40.882 & 42.195 \\
$n$ Avrami exponent & 1.53 & 1.48 & 1.46
\end{tabular}

\section{Conclusions}

The kinetics of precipitation and dissolution of GP zone and metastable phase in Al-Cu alloys was determined by a non-isothermal method. The temperature of precipitation of GP zone, formation of $\theta^{\prime} / \theta$ and dissolution of $\theta$ was found to be around 120,280 and $312^{\circ} \mathrm{C}$, respectively. The activation energies of GP zone precipitation, formation of $\theta^{\prime} / \theta$ and dissolution of $\theta^{\prime}$ were 26 , 105 and $77 \mathrm{~kJ} \mathrm{~mol}^{-1}$, respectively. The growth morphology parameters $n$ and $m$ are both about 1.5.

\section{References}

[1] S.Y. Hu, M.I. Baskes, M. Stan, L.Q. Chen, Acta Mater. 54, 4699 (2006).

[2] E. Hornbogen, E.A. Starke Jr., Acta. Metal. Mater. 41, 1 (1993).

[3] S.K. Son, M. Takeda, M. Mitome, Y. Bando, T. Endo, Mater. Lett. 59, 629 (2005).

[4] M. Karlik, B. Jouffrey, Acta Mater. 45, 3251 (1997).

[5] L. Loechte, A. Gitt, G. Gottstein, I. Hurtado, Acta Mater. 48, 2969 (2000).

[6] L. Bourgeois, C. Dwyer, M. Weyland, J.F. Nie, B.C. Muddle, Acta Mater. 59, 7043 (2011).

[7] J.B. Friauf, J. Am. Chem. Soc. 49, 3107 (1927).

[8] J.L. Murray, Int. Met. Rev. 30, 211 (1985).

[9] A. Gaber, N. Afify, M.S. Mostafa, Gh. Abbady, J. Alloys. Comp. 477, 295 (2009).

[10] H.E. Kissinger, J. Res. Natl. Bur. Stand. 57, 217 (1956).

[11] T. Ozawa, Thermochimica Acta 203, 159 (1992).

[12] P.G. Boswell , Scripta Metall. 11, 701 (1977).

[13] B. Khamel, F. Sahnoune, M. Fatmi, N. Brihi, Acta Phys. Pol. A 131, 133 (2017).

[14] M. Fatmi, B. Ghebouli, M.A. Ghebouli, T. Chihi, E. Ouakdi, Z. Heiba, Chinese J. Phys. 51, 1019 (2013).

[15] K. Matusita, K. Miura, T. Komatsu, Thermochim. Acta 88, 283 (1985). 